\title{
The potential of disproportionate growth of tricuspid valve after decompression of the right ventricle in patients with pulmonary atresia and intact ventricular septa
}

\author{
Shu-Chien Huang, MD, ${ }^{a}$ Kozo Ishino, MD, ${ }^{\mathrm{b}}$ Shingo Kasahara, MD, ${ }^{\mathrm{b}}$ Ko Yoshizumi, MD, \\ Yasuhiro Kotani, MD, ${ }^{\mathrm{b}}$ and Shunji Sano, $\mathrm{MD}^{\mathrm{b}}$
}

\begin{abstract}
Objective: Tricuspid valve size is the major determinant of outcomes for patients with pulmonary atresia with intact ventricular septum. Lack of right ventricle-pulmonary artery continuity is associated with poor tricuspid valve growth (decrement in Z-value). However, most reports did not show evidence for disproportionate growth of the tricuspid valve after establishment of right ventricle-pulmonary artery continuity.
\end{abstract}

\begin{abstract}
Methods: We studied 40 patients with pulmonary atresia with intact ventricular septum who underwent initial right ventricular decompression for planned staged repair. The initial $Z$-value of the tricuspid valve diameter (Zt1) was obtained from the echocardiography-derived normal value. The late $\mathrm{Z}$-value $(\mathrm{Zt} 2)$ was measured before definitive repair or the last available $Z$-value, if definitive repair was not yet reached. The factors associated with the changes of $\mathrm{Z}$-values $(\mathrm{Zt} 2-\mathrm{Zt} 1)$ were analyzed.
\end{abstract}

\begin{abstract}
Results: The mean initial tricuspid Z-value (Zt1) was $-6.2 \pm 3.5$. After treatment $(\mathrm{Zt} 2)$, the mean $\mathrm{Z}$-value was $-6.0 \pm 3.4(\mathrm{n}=34)$. Overall, the tricuspid Z-values did not change. Individually, the change in Z-value (Zt2 $\mathrm{Zt1})$ was larger than +2 in $11(32 \%)$ patients and smaller than -2 in $6(18 \%)$ patients. Increases in $\mathrm{Z}$-value $(\mathrm{Zt} 2-\mathrm{Zt} 1)$ were significantly associated with right ventricular pressure/left ventricular pressure ratio measured after initial palliation $(r=-0.54 ; P=.001)$ and the initial tricuspid valve $\mathrm{Z}$-value $(\mathrm{Zt} 1)(r=-0.40 ; P=.02)$.
\end{abstract}

Conclusions: Disproportional growth of the tricuspid valve can occur, especially in patients with small tricuspid valves and lower right ventricular pressures after decompression. The findings support the possibility of neonates with small tricuspid valves undergoing biventricular repair after right ventricular decompression surgery.

Pulmonary atresia with an intact ventricular septum (PA-IVS) is an uncommon congenital heart disease with a variable degree of right ventricular (RV) hypoplasia and coronary artery anomalies. Patients with RV-dependent coronary circulation, which contradicts decompression of the $\mathrm{RV}$, should be better managed with single ventricular circulation (Fontan-type repair). Otherwise, achieving biventricular repair with good functional status and low systemic venous pressure is the ideal goal. For biventricular circulation to be achieved, the tricuspid valve and RV must have adequate size to support pulmonary blood flow.

From the Department of Cardiovascular Surgery, ${ }^{a}$ National Taiwan University Hospital, Taipei, Taiwan, and the Department of Cardiovascular Surgery, ${ }^{\text {b }}$ Okayama University Hospital, Okayama University Graduate School of Medicine and Dentistry, Okayama, Japan.

Shu-Chien Huang was supported by a grant from National Taiwan University Hospital, Taipei, Taiwan, for study in Okayama, Japan, from April 2006 to September 2006.

Received for publication Oct 24, 2008; revisions received Feb 26, 2009; accepted for publication May 15, 2009.

Address for reprints: Shunji Sano, MD, Professor and Chairman, Department of Cardiovascular Surgery, Okayama University Graduate School of Medicine, Dentistry and Pharmaceutical Sciences, 2-5-1 Shikata-cho, Okayama, 700-8558, Japan (E-mail: s_sano@cc.okayama-u.ac.jp).

J Thorac Cardiovasc Surg 2009;138:1160-6

$0022-5223 / \$ 36.00$

Copyright (c) 2009 by The American Association for Thoracic Surgery

doi:10.1016/j.jtcvs.2009.05.015
Previous studies of PA-IVS showed that RV and tricuspid valve diameters had poorer growth when RV-pulmonary artery continuity was not achieved..$^{1-3}$ For better RV growth, the initial RV outflow procedure (surgically or percutaneously) with or without systemic-pulmonary shunting is the most commonly used repair strategy. ${ }^{4-7}$

There are many reports on increased RV volume after surgical or catheter-based RV decompression procedures, but there is a paucity of similar data describing the growth of tricuspid valves. ${ }^{2,5,8-10}$

Inasmuch as a small tricuspid valve causes limited RV inflow and the tricuspid valve diameter is considered the determinant for patients to undergo single ventricle or biventricular repair, we reviewed the data at our institution to see whether the tricuspid valve had "disproportionate enlargement" compared with somatic growth after decompression of the RV. We also wanted to identify the factors associated with growth of the tricuspid valve after RV decompression surgery and reviewed the late follow-up echocardiographic data to see whether the tricuspid valves continued to grow after biventricular repair.

\section{PATIENTS AND METHODS \\ Patient Population \\ Between March 1993 and June 2006, we identified 40 infants with a diagnosis of PA-IVS who underwent RV decompression in our institution,}




$$
\begin{aligned}
& \text { Abbreviations and Acronyms } \\
& \begin{aligned}
\text { BSA } & =\text { body surface area } \\
\text { LVP } & =\text { left ventricular pressure } \\
\text { PA- IVS } & =\text { pulmonary atresia with intact } \\
& \text { ventricular septum } \\
\text { RV } & =\text { right ventricle (ventricular) } \\
\mathrm{RVP} & =\text { right ventricular pressure } \\
\mathrm{t} 1 & =\text { first time point } \\
\mathrm{t} 2 & =\text { second time point } \\
\mathrm{TV} & =\text { tricuspid valve } \\
\mathrm{TVD} & =\text { tricuspid valve diameter } \\
\mathrm{Zt} 1 & =\text { initial Z-value } \\
\mathrm{Zt} 2 & =\text { Z-value after treatment }
\end{aligned}
\end{aligned}
$$

and all were included in this study. Patients with critical pulmonary stenosis (pinhole patency of the pulmonary valve, suprasystemic pressures in the $\mathrm{RV}$, and duct-dependent pulmonary circulation) and intact ventricular septa were also included $(n=5)$ because, in all other respects, they were similar to patients with PA-IVS. Patients with no detectable infundibulum or RVdependent coronary circulation did not undergo RV decompression and thus were not included in this study.

\section{Measurements}

We reviewed the echocardiographic and cardiac catheterization data. The tricuspid valve diameter was measured from echocardiograms at its maximum in diastole from the apical 4-chamber view. This tricuspid valve diameter was then expressed as a percentage of the normal mean and the $\mathrm{Z}$-score obtained with the formula from the echocardiography-derived normal value calculated using body surface area ${ }^{11}$ :

$$
\ln (\mathrm{TVD})=1.08+0.4945 \cdot \ln (\mathrm{BSA})
$$

where TVD $=$ tricuspid diameter $(\mathrm{cm})$ and BSA $=$ body surface area $\left(\mathrm{m}^{2}\right)$.

$$
\text { Z-value }=(\ln [\text { observed TVD }]-\ln [\text { mean normal TVD }]) / 0.08121
$$

where TVD is as defined earlier.

Direct measurements obtained during catheterization were used to estimate the RV/left ventricular systolic pressure (RVP/LVP) ratio. RV volumes were calculated from biplane cineangiograms using the Simpson rule, as previously described. ${ }^{12} \mathrm{RV}$ end-diastolic volume was corrected for BSA and was expressed as a percentage of the predicted normal using the formula derived by Nakazawa and colleagues. ${ }^{13}$

$$
\begin{aligned}
\text { Predicted normal RV end-diastolic volume }(\mathrm{mL})= & 75.1 \\
& \times \mathrm{BSA}\left(\mathrm{m}^{2}\right)^{1.43}
\end{aligned}
$$

\section{Management of the Patients}

All patients were treated with prostaglandin $\mathrm{E}_{1}$ infusion, and balloon atrial septostomy was performed during cardiac catheterization in most of the patients before surgery.

Initial procedures. Initial management was transarterial pulmonary valvotomy and placement of a systemic-pulmonary shunt, without cardiopulmonary bypass, as previously reported ${ }^{14}$ for the majority $(95 \%, 38 / 40)$ of the patients. The pulmonary valve was penetrated and further opened with a 3- or 4-mm Hegar dilator through the incision in the main pulmonary artery; a polytetrafluoroethylene tube (Gore-Tex tube; W. L. Gore \& Associates, Inc, Flagstaff, Ariz) was anastomosed to the left subclavian artery and the incision in the pulmonary trunk. The ductus arteriosus was then ligated. The other 2 patients underwent percutaneous valvotomy and RV outflow tract patching as their initial treatments, respectively.

Secondary procedures. Diagnostic postoperative cardiac catheterizations were performed after the initial RV decompression surgery $(\mathrm{n}=33)$. The interval between operation and catheterization was $0.76 \pm 0.54$ years At this stage, an RVP/LVP ratio greater than 0.5 was an indication for balloon pulmonary valvuloplasty $(n=20)$. For patients with an $R V$ end-diastolic volume less than $50 \%$ of the predicted normal value estimated at the last cardiac catheterization, we performed an "RV overhaul" procedure $(n=6) .{ }^{14,15}$ The $R V$ overhaul procedure included repeat pulmonary valvotomy, transatrial and transpulmonary resection of the hypertrophied infundibular muscle, and adjustment of an interatrial communication. To increase blood flow through the tricuspid valve, we partially closed the atrial septal defect, keeping right atrial pressure less than $15 \mathrm{~mm} \mathrm{Hg}$, and maintained a gradient across the atrial septal defect of less than $10 \mathrm{~mm} \mathrm{Hg}$.

Definitive repair. We generally consider a tricuspid valve diameter larger than $60 \%(Z=-6.3)$ of the normal mean as the indication for biventricular repair. If the tricuspid valve is less than $50 \%$ of normal mean ( $Z$ $<-8.5$ ), we consider single ventricle repair or one-and-a-half ventricle repair. The borderline cases (tricuspid valve size between $50 \%$ and $60 \%$ of normal, $\mathrm{Z}=-8.5$ to -6.3 ) were judged on intraoperative findings. We have the tendency to perform biventricular repair whenever possible. The surgical procedure included construction of an unobstructed RV outflow and closure of the intra-atrial communication and the systemic-pulmonary shunt. We used various techniques including pulmonary valve repair, resection of obstructing infundibular muscle, excision of hypertrophied RV muscle to enlarge the cavity, and monocuspid transannular patching to achieve a normal-sized outflow tract. During biventricular repair or one-and-a-half ventricle repair with a marginal tricuspid valve diameter, we used an adjustable stitch to close the final interatrial communication defect for better judgment after weaning the patient from cardiopulmonary bypass. We left a small fenestration during closure of the interatrial septum in 14 patients, and 12 of them had spontaneous closure of the communication on followup echocardiograms.

After definitive repair, the patients were monitored echocardiographically. Among the 27 patients who underwent biventricular repair, cardiac catheterization data were available for 17 and follow-up echocardiographic data were available for 24 patients.

\section{Data Analysis and Statistical Methods}

We compared the tricuspid valve Z-values at different time points to discern changes in tricuspid valve diameter. The first time point (t1) was defined as the $\mathrm{Z}$-value obtained from the initial echocardiogram. The second time point $(\mathrm{t} 2)$ was defined as the $\mathrm{Z}$-value just before definitive repair if the patient underwent definitive repair. Otherwise, we chose the Z-value from the most recent echocardiogram among patients in whom definitive repair was not completed (ie, those with mixed systemic and pulmonary circulation). The third time point ( $\mathrm{t} 3$ ) was defined as the $\mathrm{Z}$-value from the most recent echocardiogram among patients in whom biventricular repair was completed. Disproportionate tricuspid valve growth was defined as the change in tricuspid valve Z-values. Thus increase of Z-value indicated the outgrowth of the tricuspid valve according to the BSA, and decrease of Z-value indicated the "shrinkage" of the tricuspid valve to the BSA.

To examine whether lower RVP influenced the growth of the tricuspid valve, we examined the relationship of RVP/LVP after initial palliation to differences in Z-scores of tricuspid valves. After biventricular repair, the hemodynamic data were reviewed and correlated with the size of the tricuspid valve.

Results are presented as means \pm SDs or percentages. The data were analyzed with SPSS software (SPSS Inc, Chicago, Ill). The paired Student $t$ tests were used for comparing continuous variables for the same patient. The Wilcoxon signed rank test was used for comparison of continuous variables. Correlation was analyzed by linear correlation modeling, computing 
the Pearson correlation coefficient $(r)$ and nonparametric regression analysis (categorical variables), as appropriate.

\section{RESULTS}

\section{Demographic Data}

Among the 40 patients ( 21 boys and 19 girls), the mean age at the first operation was $28.6 \pm 17.2$ days; the average body weight was $3.0 \pm 0.6 \mathrm{~kg}$.

There were 2 deaths after the stage I operations, and 1 patient was lost to follow-up. Two patients were waiting for their next operations after initial valvotomy and shunt placement. The remaining 35 patients received further treatment as follows: Four patients received bidirectional Glenn shunts, and 1 of these infants died. Two patients were waiting for definitive repair after RV overhaul, and 29 patients underwent definitive repairs.

Mean patient age at definitive surgery was $2.4 \pm 0.9$ years. The definitive repairs included biventricular repair $(\mathrm{n}=27)$, Fontan circulation $(\mathrm{n}=1)$, and one-and-a-half ventricle repair $(n=1)$. One late death after biventricular repair occurred 6 months after surgery; the cause of death was not clearly known (presumed arrhythmia). The overall median follow-up period after the initial procedure was 6.8 years (1-13 years).

\section{Tricuspid Valve Growth}

There were 34 patients with Z-values at both $\mathrm{t} 1$ and $\mathrm{t} 2$ available for analysis. The initial mean tricuspid valve $\mathrm{Z}$ value $(\mathrm{Zt} 1)$ was $-6.2 \pm 3.5$, which corresponded to a $\mathrm{Z}$ value of $-1.9 \pm 1.5$ by autopsy-derived nomogram. ${ }^{16}$ After treatment ( $\mathrm{Zt2}$ ), the $\mathrm{Z}$-value was $-6.0 \pm 3.4$ (Figure 1). The age at the $\mathrm{t} 2$ point was $2.2 \pm 1.1$ years old. Overall, the average of tricuspid valve Z-value did not change $(P>$ .05 , paired Student $t$ test). The RV volume increased from $44 \% \pm 34 \%$ to $57 \% \pm 30 \%$ of the normal value $(P<0.05)$.

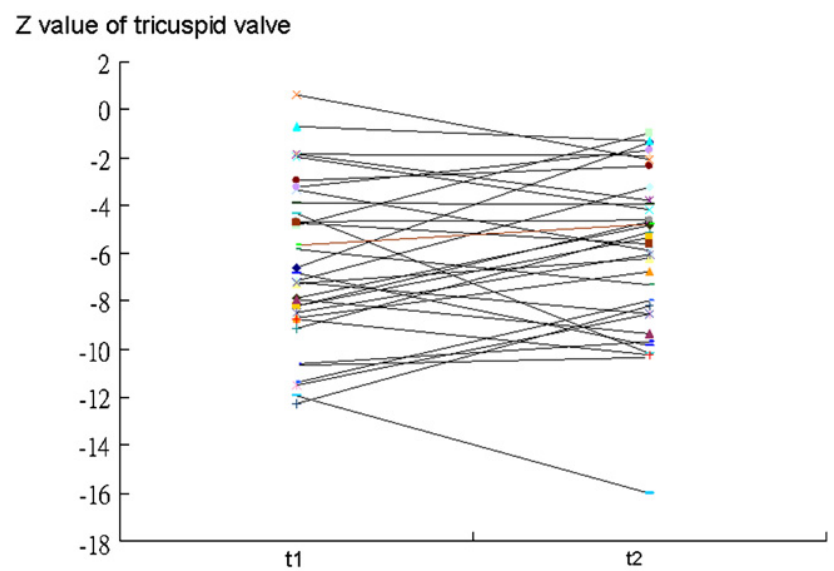

FIGURE 1. The tricuspid valve Z-value at the initial evaluation $(t 1)$ and after treatment $(t 2)$.
TABLE 1. The factors analyzed for the change of tricuspid valve Z-value (Zt2-Zt1)

\begin{tabular}{lcc}
\hline \multicolumn{1}{c}{ Variables } & $\begin{array}{c}\text { Pearson } \\
\text { correlation }\end{array}$ & $\begin{array}{c}\text { Univariate } \\
\boldsymbol{P} \text { value }\end{array}$ \\
\hline Initial evaluation (t1) & & \\
Body surface area & -0.018 & .92 \\
Z-value of TV & -0.40 & .02 \\
RV volume (\% of normal) & -0.32 & .13 \\
Tricuspid regurgitation & -0.05 & .79 \\
Presence of sinusoid & -0.307 (Spearman rho) & .099 \\
Age at first operation & -0.11 & .53 \\
Second evaluation (t2) & & .13 \\
Age at evaluation (t2) & 0.27 & .58 \\
RV volume (\% of normal) & -0.10 & .0013 \\
RVP/LVP & -0.54 & \\
\hline
\end{tabular}

$T V$, Tricuspid valve; $R V$, right ventricular; $R V P$, right ventricular pressure; $L V P$, left ventricular pressure.

Comparing the tricuspid valve $Z$-value after treatment (Zt2) with initial Z-value (Zt1) for individual patients showed that the change in $\mathrm{Z}$-value $(\mathrm{Zt} 2-\mathrm{Zt} 1)$ was larger than +2 in 11 $(32 \%)$ patients and smaller than -2 in $6(18 \%)$ patients. The other $17(50 \%)$ patients had Z-value changes within \pm 2 . The increases in $\mathrm{Z}$-values $(\mathrm{Zt} 2-\mathrm{Zt} 1)$ were not related to patient age at initial operation, presence of sinusoid communication, or severity of tricuspid regurgitation (Table 1) The increases in Z-values (Zt2-Zt1) were significantly negatively associated with RVP/LVP measured after initial palliation (Figure 2) $(r=-0.54 ; P=.0013)$. The increases were also more marked among patients with initially small tricuspid valve $\mathrm{Z}$-values $(r=-0.40 ; P=.02)$ (Figure 3 ).

Among the 27 patients in whom biventricular circulation was achieved, the mean initial Z-value (Zt1) was $-5.8 \pm 3.6$, and the mean $\mathrm{Z}$-value was $-4.9 \pm 2.63(P<.05)$ when they received biventricular repair. The distributions of tricuspid valve size with regard to $50 \%$ and $60 \%$ of normal value

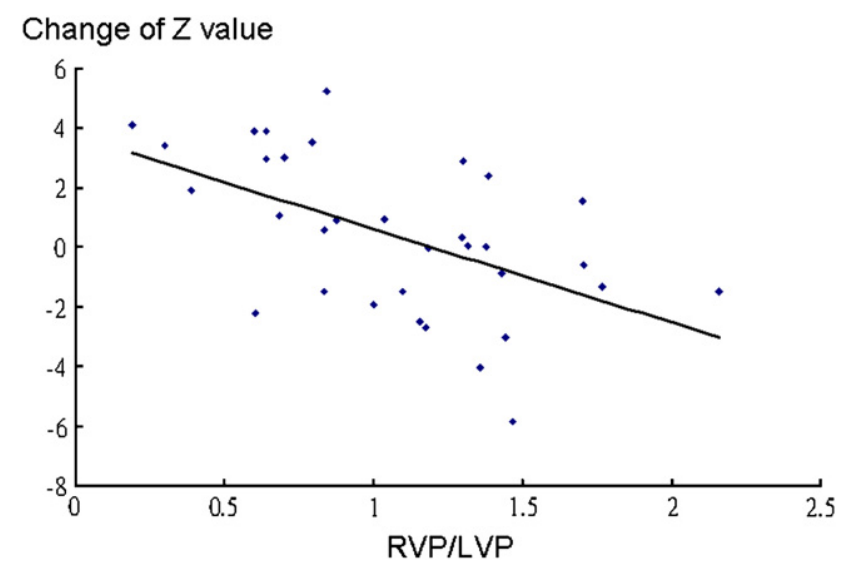

FIGURE 2. The change of $\mathrm{Z}$-value $(\mathrm{Z} \mathrm{t} 2-\mathrm{Z} \mathrm{t} 1)$ showed negative correlation with the right ventricular pressure/left ventricular pressure $(R V P / L V P)$ measured after initial palliation $(P=.0013)$. 


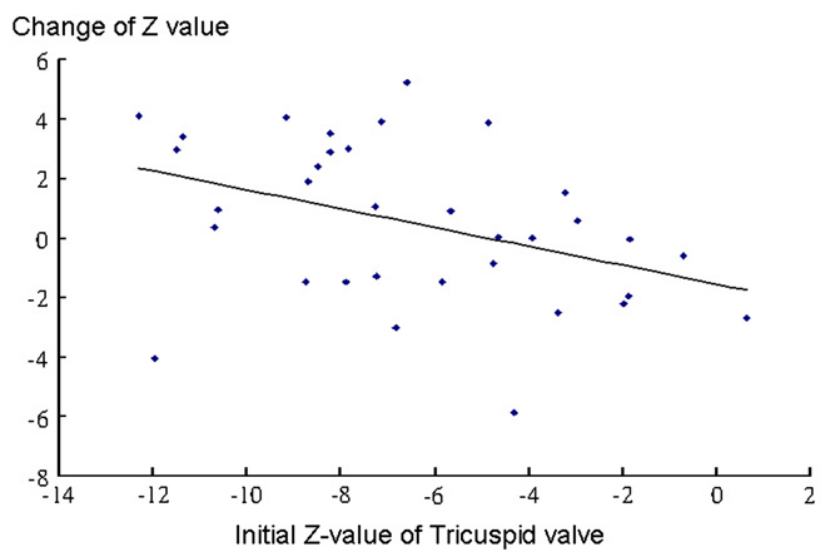

FIGURE 3. The change of $\mathrm{Z}$-value $(\mathrm{Zt} 2-\mathrm{Zt} 1)$ showed negative correlation with the initial tricuspid valve $\mathrm{Z}$-value $(P=.02)$.

(proposed criteria for biventricular repair) in these 27 patients are depicted in Table 2. Among the 27 patients, 13 $(48 \%)$ had initial Z-values less than -6.3 , and 7 of them had increased Z-values to more than -6.3 at the stage of definitive repair.

Seventeen patients underwent follow-up cardiac catheterization after definitive repairs (mean of $1.66 \pm 1.11$ years after repair). Their right atrial pressures negatively correlated with tricuspid valve $\mathrm{Z}$-value (Pearson $r=-0.49 ; P=.038$ ) (Figure 4). All of these patients had right atrial pressures of less than $12 \mathrm{~mm} \mathrm{Hg}$, except for 1 patient with a right atrial pressure of $14 \mathrm{~mm} \mathrm{Hg}$. This particular patient had a tricuspid valve diameter equal to $48 \%$ of normal (Z-value $=-9$ ), but she was considered a high-risk Fontan candidate because of left pulmonary vein occlusion after reimplantation for anomalous return. She was still alive at 4 years of follow-up.

Among the patients who underwent successful biventricular repairs, tricuspid valve $\mathrm{Z}$-values further increased an average of $1.14 \pm 1.09$ by $4.9 \pm 3.2$ years after definitive surgery $(P<.001, \mathrm{n}=24)$. We could not find any specific parameter associated with the "enlargement" of the tricuspid valve after biventricular repair.

\section{DISCUSSION}

In this study, we found that the disproportionate growth of the tricuspid valve existed in some patients with PA-IVS and related to the small initial tricuspid valve diameter and

TABLE 2. The distribution of tricuspid valve size among the 27 patients who received biventricular repair

\begin{tabular}{lccc}
\hline & \multicolumn{3}{c}{$\begin{array}{c}\text { Tricuspid valve size } \\
\text { Z-value (\% normal) }\end{array}$} \\
\cline { 2 - 4 } $\begin{array}{c}\text { Timing of } \\
\text { echocardiography }\end{array}$ & $\begin{array}{c}\mathbf{Z}<-\mathbf{8 . 5} \\
(<\mathbf{5 0} \%)\end{array}$ & $\begin{array}{c}-\mathbf{8 . 5} \leq \mathbf{Z}<-\mathbf{6 . 3} \\
\mathbf{( 5 0} \% \mathbf{- 6 0} \%)\end{array}$ & $\begin{array}{c}\mathbf{Z} \geq-\mathbf{6 . 3} \\
(>\mathbf{6 0} \%)\end{array}$ \\
\hline Initial evaluation (t1) & 6 & 7 & 14 \\
At biventricular repair (t2) & $2 *$ & 4 & 21 \\
\hline *The 2 patients have Z-values $=-10.2$ and -9.7, respectively.
\end{tabular}

*The 2 patients have $\mathrm{Z}$-values $=-10.2$ and -9.7 , respectively.

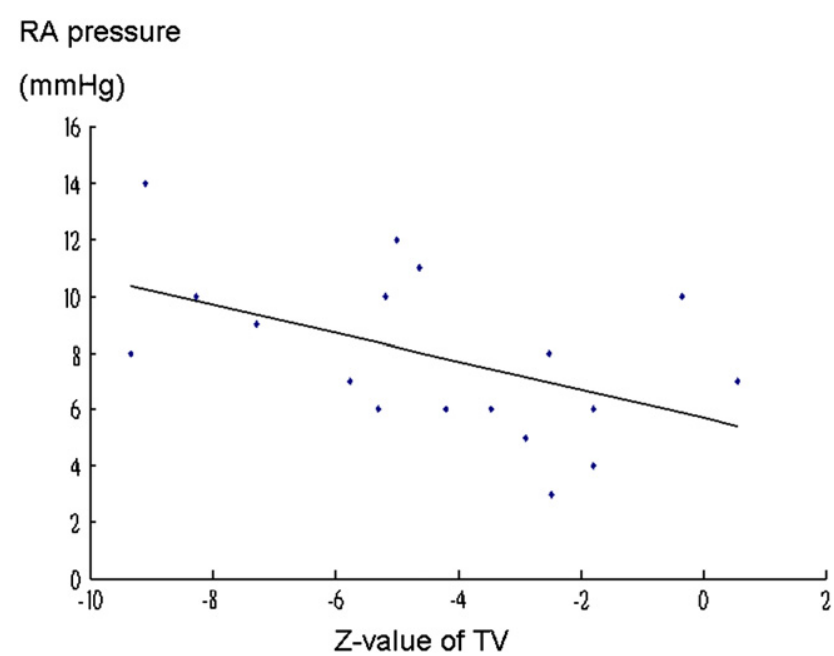

FIGURE 4. Among the patients who received follow-up catherization after biventricular repair $(\mathrm{n}=17)$, the right atrial $(R A)$ pressure is negatively correlated with the tricuspid valve (TV) size after biventricular repair. The $\mathrm{Z}$-value was measured by echocardiography when the patient received follow-up catheterization.

the RVP/LVP. This finding was never been well shown in previous studies, and some texts state that "there is no evidence that disproportionate enlargement occurs as growth of the child proceeds, no matter what the surgical procedure. ${ }^{17}$ Even in the recent study by Bryant and associates, ${ }^{18} \mathrm{RV}$ sinus myectomy was a proposed strategy for early biventricular repair. Although the RV size increased, the Z-value of the tricuspid valve did not change appreciably. However, the Z-value they compared (before and after myectomy) started at the median age of 1.25 years, not the neonatal periods, as in our cases.

Because of the rarity of PA-IVS, single institution experience is generally limited by the small number of cases; the two largest studies are Congenital Heart Surgeons Society studies. ${ }^{1,19}$ However, these studies did not provide data about late tricuspid valve diameter Z-values. Hanley and coworkers ${ }^{1}$ summarized 53 patients from 4 studies. ${ }^{2,3,8,20}$ The Z-values decreased without RV outflow tract procedures, and in patients with RV outflow tract procedures, the overall $\mathrm{Z}$-value remained unchanged. It is of note that $15 \%$ of these patients experienced a $Z$-value change of +2 and $10 \%$ experienced a change of +4 , but this predictor of tricuspid valve growth was not known at the time of these studies.

Similarly, we also found that the mean overall Z-value did not change significantly, but the $\mathrm{Z}$-value change was quite variable among individual patient. We also found that lower RVP and smaller initial Z-values were associated with greater increases in $\mathrm{Z}$-values at their definitive repair.

\section{RVP and Growth of Tricuspid Valve}

We looked for similar findings in other studies. In the report by Bull and associates ${ }^{21}$ in 1994, half of the 
TABLE 3. The changes of $Z$-value of the tricuspid valve among the patients with pulmonary atresia-intact ventricular septum by the right ventricular pressure after decompression procedure

\begin{tabular}{lcc}
\hline & Hypertensive RV & Hypotensive RV \\
\hline Increase in Z-value & 6 & 6 \\
Decrease in Z-value & 8 & 3 \\
No change in Z-value & 1 & 1 \\
\hline Hypertensive $R V$, Suprasystemic right ventricular pressure; hypotensive RV, right ven- \\
tricular pressure lower than systemic pressure. (Adapted from Bull et al ${ }^{21}{ }^{\text {[Figure 5].) }}$
\end{tabular}

decompressed RVs achieved tricuspid valve growth disproportionate to somatic growth. Reviewing the presented data, ${ }^{21}$ there were 15 patients with hypertensive RVs (suprasystemic RVP) and 10 patients with hypotensive RVs after $\mathrm{RV}$ decompression. The Z-value enlarged in only $40 \%$ of the hypertensive RVs but in $60 \%$ of hypotensive RVs. Thus, hypotensive RVs tended to have better tricuspid valve growth, although this result did not reach statistical significance (Table 3).

We combined the reports from Patel, ${ }^{3}$ Shaddy, ${ }^{10}$ and their associates, in which the RVP and tricuspid valve diameter were presented. We included patients with RV-pulmonary artery continuity and recalculated the Z-values and the changes in $Z$-values ( $n=26$, one outlier was excluded). We found that the change in $\mathrm{Z}$-value was negatively correlated with postoperative RVP $(r=-0.552 ; P=.003)$ and initial tricuspid valve Z-value $(r=-0.579 ; P=.002)$ (Figure 5).

These data support our finding that "disproportionate" tricuspid valve growth occurred and that lower RVP and smaller initial Z-value were predictors for better tricuspid valve growth.

The mechanisms of RV and tricuspid valve growth are not clearly understood. Experimental pulmonary stenosis in fetal lambs induced either greatly reduced or markedly increased RV volume. Ventricular enlargement appears to be associated with a large ventricular volume load resulting from tricuspid valve regurgitation. A small competent tricuspid valve is associated with reduced flow through the ventricle owing to outflow obstruction and a small RV. ${ }^{22}$ This experiment suggests that cardiac chamber development is influenced by blood flow, at least in the prenatal period. In our study, lower RVP indicated a well-opened outflow tract and, thus, increased flow through the RV; better tricuspid valve growth in patients with lower RVP is comparable with the flow-mediated growth theory. On the other hand, decreased RVP is beneficial for coronary perfusion to the $\mathrm{RV}$ myocardium, regression of RV myocardial hypertrophy, and prevention of RV fibrosis. Furthermore, this mechanism possibly explains the better RV and tricuspid valve growth.

\section{Initial Z-Value Relationship to Tricuspid Valve Growth}

Another interesting finding of our study is that smaller $\mathrm{Z}$-values were associated with more pronounced Z-value
Change of $Z$ value

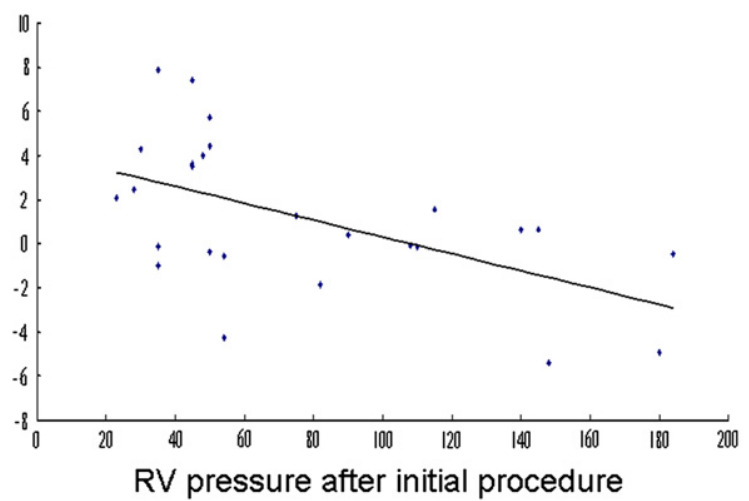

Change of $Z$ value

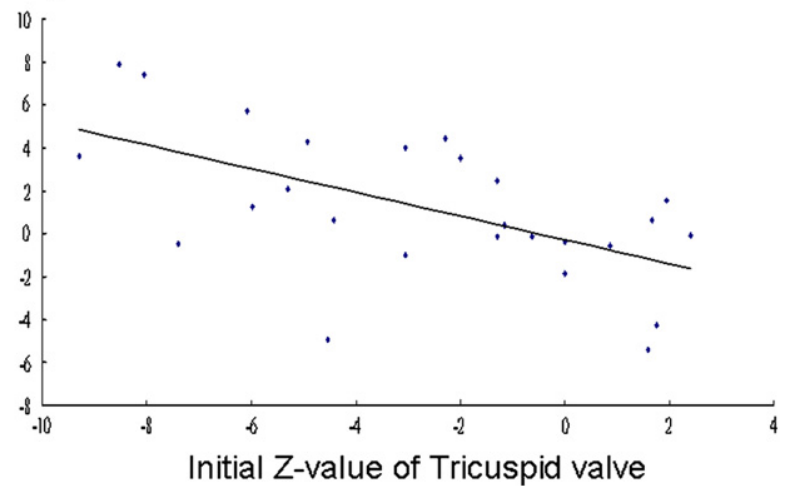

FIGURE 5. The change in tricuspid valve $Z$-value in the patients reported by Shaddy, ${ }^{10}$ Patel, ${ }^{3}$ and their associates. A, The higher right ventricular $(R V)$ pressure after initial decompression procedure is negatively correlated with tricuspid valve growth. B, The change in Z-value is also negatively correlated with the initial tricuspid valve size (Initial Z-value). (Adapted from Patel et $\mathrm{al}^{3}$ [Tables 1 and 2] and Shaddy et al ${ }^{10}$ [Table 2].)

increments. This finding is also consistent with other findings in the literature. Percutaneous valvotomy was selectively performed for patients with larger tricuspid valves. In the reports by both Humpl and associates ${ }^{5}$ (mean Z-value $=-1.33 \pm 1.58)$ and Ovaert and colleagues ${ }^{23}$ (Z-value $=$ -0.8 ; range: -1.3 to -0.4 ), the $\mathrm{Z}$-values did not increase and even decreased after percutaneous pulmonary valvotomy. In the surgical series by Shaddy and coauthors, ${ }^{10}$ the initial Z-value was $-4 \pm 4,(73 \% \pm 21 \%$ of the normal mean), and these authors reported disproportional growth of the tricuspid valve in the majority of their patients. On the basis of these findings, we believe that the overall Zvalue would not change if we included all patients, as in the previous reports, ${ }^{1,14}$ and disproportionate growth was possibly more frequently observed in patients with small initial Z-values.

\section{Z-Value of the Biventricular Circulation}

The definite tricuspid valve Z-value criterion for biventricular repair was not well established. Among the 27 
patients who received biventricular repair, $13(48 \%)$ had an initial Z-value less than-6.3, and the tricuspid valve size increased to more than -6.3 in 7 of them and between -6.3 and -8.5 in the remaining 4 (Table 2) If we arbitrarily set the Z-value greater than -6.3 as the criterion for biventricular repair, there will be 7 patients who became candidates for biventricular repair despite the initial Z-value being less than -6.3 . We suggest not abandoning biventricular repair in the neonatal period solely by the echocardiographic Zvalue of the tricuspid valve. In a recent report, Bryant and coworkers ${ }^{18}$ from Cleveland suggested a Z-value greater than -5 as the criterion for biventricular repair. In our series, inasmuch as we have a tendency to favor biventricular repair, the Z-value is smaller than in the series by Bryant and coworkers. ${ }^{18}$

\section{Follow-up Results}

In our study as in other reports, ${ }^{10,15}$ the majority of patients underwent biventricular repair when adequate growth of the tricuspid valve and RV were attained. The follow-up catheterizations showed that right atrial pressure was within the normal range, except in 1 patient with pulmonary vein stenosis, which excluded Fontan circulation. Serial echocardiography showed a further increase (mean: $1.14 \pm 1.09$ ) in tricuspid valve $Z$-value after biventricular repair. The findings suggest that the growth potential of the RV and tricuspid valve is present in some patients, which makes a biventricular repair attractive despite the fact that the tricuspid valve is initially too small to support pulmonary circulation in the neonatal period. Although patient survival in our study was good, on long-term follow-up, patients with small tricuspid valves might have higher systemic venous pressures and late atrial arrhythmia complications. The RV compliance after staged RV decompression was not completely normal ${ }^{24}$ and resulted in "restrictive" RV physiology. ${ }^{25}$ Further study is required to further clarify the best stratification for patients to undergo one, two, or one-anda-half ventricle repair.

\section{Study Limitations}

This study was retrospective and had a limited number of cases from a single center. The possibility that the Z-value change is due to the "regression to the mean" phenomenum or due to measurement error in a small neonate, which results in errors of Z-values, could not be completely excluded. Because the management strategies for PA-IVS vary from center to center, a multicenter study is required to determine whether the findings stand in patients who are treated with other surgical strategies.

\section{CONCLUSIONS}

We showed that disproportional growth of the tricuspid valve occurred, especially in patients with initially small tricuspid valves and lower RVP after decompression. The findings support the possibility of a neonate with a small tricuspid valve undergoing biventricular repair after RV decompression surgery.

We thank Dr. Fu-Chang Hu, National Center of Excellence for General Clinical Trial and Research, National Taiwan University Hospital and College of Public Health, National Taiwan University, for his help in the statistical analysis.

\section{References}

1. Hanley FL, Sade RM, Blackstone EH, Kirklin JW, Freedom RM, Nanda NC. Outcomes in neonatal pulmonary atresia with intact ventricular septum. A multiinstitutional study. J Thorac Cardiovasc Surg. 1993;105:406-23, 24-7; discussion 23-4.

2. de Leval M, Bull C, Stark J, Anderson RH, Taylor JF, Macartney FJ. Pulmonary atresia and intact ventricular septum: surgical management based on a revised classification. Circulation. 1982;66:272-80.

3. Patel RG, Freedom RM, Moes CA, Bloom KR, Olley PM, Williams WG, et al. Right ventricular volume determinations in 18 patients with pulmonary atresia and intact ventricular septum. Analysis of factors influencing right ventricular growth. Circulation. 1980;61:428-40.

4. Yoshimura N, Yamaguchi M, Ohashi H, Oshima Y, Oka S, Yoshida M, et al. Pulmonary atresia with intact ventricular septum: strategy based on right ventricular morphology. J Thorac Cardiovasc Surg. 2003;126:1417-26.

5. Humpl T, Soderberg B, McCrindle BW, Nykanen DG, Freedom RM, Williams WG, et al. Percutaneous balloon valvotomy in pulmonary atresia with intact ventricular septum: impact on patient care. Circulation. 2003;108:826-32.

6. Giglia TM, Jenkins KJ, Matitiau A, Mandell VS, Sanders SP, Mayer JE Jr, et al. Influence of right heart size on outcome in pulmonary atresia with intact ventricular septum. Circulation. 1993;88(5 Pt 1):2248-56.

7. Jahangiri M, Zurakowski D, Bichell D, Mayer JE, del Nido PJ, Jonas RA. Improved results with selective management in pulmonary atresia with intact ventricular septum. J Thorac Cardiovasc Surg. 1999;118:1046-55.

8. Hanseus K, Bjorkhem G, Lundstrom NR, Laurin S. Cross-sectional echocardiographic measurements of right ventricular size and growth in patients with pulmonary atresia and intact ventricular septum. Pediatr Cardiol. 1991;12:135-42.

9. Lewis AB, Wells W, Lindesmith GG. Evaluation and surgical treatment of pulmonary atresia and intact ventricular septum in infancy. Circulation. 1983;67: $1318-23$.

10. Shaddy RE, Sturtevant JE, Judd VE, McGough EC. Right ventricular growth after transventricular pulmonary valvotomy and central aortopulmonary shunt for pulmonary atresia and intact ventricular septum. Circulation. 1990;82(5 Suppl): IV157-63.

11. Daubeney PE, Blackstone EH, Weintraub RG, Slavik Z, Scanlon J, Webber SA Relationship of the dimension of cardiac structures to body size: an echocardiographic study in normal infants and children. Cardiol Young. 1999;9:402-10

12. Graham TP Jr, Jarmakani JM, Atwood GF, Canent RV Jr. Right ventricular volume determinations in children. Normal values and observations with volume or pressure overload. Circulation. 1973;47:144-53.

13. Nakazawa M, Marks RA, Isabel-Jones J, Jarmakani JM. Right and left ventricular volume characteristics in children with pulmonary stenosis and intact ventricular septum. Circulation. 1976;53:884-90.

14. Sano S, Ishino K, Kawada M, Fujisawa E, Kamada M, Ohtsuki S. Staged biventricular repair of pulmonary atresia or stenosis with intact ventricular septum. Ann Thorac Surg. 2000;70:1501-6.

15. Pawade A, Capuani A, Penny DJ, Karl TR, Mee RB. Pulmonary atresia with intact ventricular septum: surgical management based on right ventricular infundibulum. J Card Surg. 1993;8:371-83.

16. Rowlatt UR, Rimoldi HJA, Lev M. The quantitative anatomy of the normal child's heart. Pediatr Clin North Am. 1963;10:499-588.

17. Pulmonary atresia and intact ventricular septum. Chapter 26. In: Kouchoukos N, Blackstone E, Doty D, Hanley F, Karp R, eds. Kirklin and Barratt-Boyes cardiac surgery. 3rd ed. New York: Churchill Livingstone; 2003. p.1104.

18. Bryant R 3rd, Nowicki ER, Mee RB, Rajeswaran J, Duncan BW, Rosenthal GL, et al. Success and limitations of right ventricular sinus myectomy for pulmonary atresia with intact ventricular septum. J Thorac Cardiovasc Surg. 2008;136: 735-42, 42e1-e2.

19. Ashburn DA, Blackstone EH, Wells WJ, Jonas RA, Pigula FA, Manning PB, et al Determinants of mortality and type of repair in neonates with pulmonary atresia 
and intact ventricular septum. $J$ Thorac Cardiovasc Surg. 2004;127:1000-7; discussion 1007-8.

20. Metzdorff MT, Pinson CW, Grunkemeier GL, Cobanoglu A, Starr A. Late right ventricular reconstruction following valvotomy in pulmonary atresia with intact ventricular septum. Ann Thorac Surg. 1986;42:45-51.

21. Bull C, Kostelka M, Sorensen K, de Leval M. Outcome measures for the neonatal management of pulmonary atresia with intact ventricular septum. $J$ Thorac Cardiovasc Surg. 1994;107:359-66.

22. Rudolph AM. Myocardial growth before and after birth: clinical implications. Acta Paediatr. 2000;89:129-33.
23. Ovaert C, Qureshi SA, Rosenthal E, Baker EJ, Tynan M. Growth of the right ventricle after successful transcatheter pulmonary valvotomy in neonates and infants with pulmonary atresia and intact ventricular septum. J Thorac Cardiovasc Surg. 1998;115:1055-62.

24. Graham TP Jr, Bender HW, Atwood GF, Page DL, Sell CG. Increase in right ventricular volume following valvulotomy for pulmonary atresia or stenosis with intact ventricular septum. Circulation. 1974;50(2 Suppl):II69-79.

25. Redington AN, Penny D, Rigby ML, Hayes A. Antegrade diastolic pulmonary arterial flow as a marker of right ventricular restriction after repair of pulmonary atresia with intact septum and critical pulmonary valve stenosis. Cardiol Young. 1992;2:382-6. 